\title{
Hepatic Cytochrome P450 as Biomarkers of Cypermethrin Toxicity in Freshwater Teleost, Channa punctatus (Bloch)
}

\author{
Dawa Bhutia, Benoy Kishore Rai and Joydeb Pal* \\ Ecology and Toxicology Laboratory; Department of Zoology; University of North Bengal; Siliguri, West Bengal - \\ India
}

\begin{abstract}
In this study, Channa punctatus was treated with sub-lethal concentration of cypermethrin $(6.6 \mu \mathrm{g} / \mathrm{L})$ for 5,10 and 15 days and its effect on total CYP 450 and the activity of hepatic CYP450 isoforms measured. Total CYP450 content and CYPIA mediated EROD activity was significantly induced $(p<0.05)$ in all three treated groups compared to control whereas only 15 days treated group showed significant induction in CYP2B mediated N,Ndimethylaniline demethylase activity. CYP2E1 mediated aniline hydroxylase activity showed only a marginal increase while there was inhibition of CYP3A4 mediated erythromycin demethylase activity. Liver somatic index (LSI) also showed a marginal increase in all the treated groups. Results showed differential induction of CYP1A, $C Y P 2 B, C Y P 2 E 1$ and inhibition of CYP3A4 isoform due to cypermethrin treatment in $\mathrm{C}$. punctatus. The study clearly showed CYPIA isoform as the most responsive and important biomarker for monitoring the aquatic pollution.
\end{abstract}

Key words: cypermethrin, cytochrome P450, fish, Channa punctatus, biomarker

\section{INTRODUCTION}

Pesticide usage is a critical concern which may have an adverse effect on the delicate ecosystem because of their toxicity, persistency and tendency to concentrate in organisms as they move up in the food chain, increase their toxicity to fish, birds and other wildlife and, in turn to man. While the pesticides are instrumental in achieving significant increase in crop productivity, they also cause serious ecological hazards to the non-target animals especially the fish, which forms an important part of food chain for various animals including human beings (Sharma and Ansari 2011).

Synthetic pyrethroids have been introduced over the past two decades for agricultural and domestic use as replacements for more toxic pesticides, such as chlorinated hydrocarbons, organophosphates and carbamates. Cypermethrin is a type of cyanophenoxybenzyl pyrethroid and is categorized as restricted use pesticide by US EPA because of its high toxicity to fish (Saha and Kaviraj 2009).

Fish, as a bioindicator species, plays an increasingly important role in the monitoring of water pollution because it responds with great sensitivity to the changes in the aquatic environment. Biochemical markers are measurable responses to the exposure of an organism to xenobiotics. Regarding biochemical responses in fish to aquatic pollutants, cytochrome P450 (CYP 450) is known to play a major role in the oxidative metabolism/biotransformation of a wide range of both endogenous and exogenous compounds and is considered one of the most

*Author for correspondence: paljoydeb@rediffmail.com 
important phase I biotransformation enzymes (Siroka and Drastichova 2004). The families responsible for the metabolism of xenobiotics are CYP1 to CYP3, and to a much lesser extent CYP4, whereas cytochrome P450 enzymes belonging to other families are concerned with the metabolism of endogenous substrates (Ioannides and Lewis 2004).

CYP 450 is very sensitive to a wide range of xenobiotics and is usually the first detectable and quantifiable response to environmental change, including a change in the chemical environment. Understanding of toxicological mechanisms have provided an advancement in biological tools for environmental assessments and CYP 450 family is widely studied as a biomarker for environmental contamination in aquatic ecosystems. These tools, called biomarkers, are biological responses at molecular, cellular, or organism levels and have accordingly been classified as biomarkers of exposure, effect, and susceptibility (Moore et al. 2004).

The effects of cypermethrin on commercially important Indian species of fish are poorly documented. The objective of the present study was to evaluate if activities of hepatic cytochrome P450 could be evaluated as potential biomarkers of cypermethrin toxicity to fish.

\section{MATERIALS AND METHODS}

\section{Fish}

Specimens of Channa punctatus were collected from the local fish market. Fish were acclimatized in the laboratory for a period of two weeks. After that, healthy fish (male and female) weighing approximately $35 \pm 5 \mathrm{~g}$ were transferred to glass aquarium with $50 \mathrm{~L}$ capacity in controlled light (12 hr light/12 hr dark) and aeration conditions. They were fed regularly with small pieces of chopped fish at fixed rate during the course of the experiment.

\section{Experimental design}

Fish were randomly taken in six groups (eight fish in each aquarium) each of control and treated. A sub-lethal concentration of $6.6 \mu \mathrm{g} / \mathrm{L}$ cypermethrin based on acute toxicity data (not published) generated from the laboratory experiments was used to treat the experimental fish. The water was renewed every $48 \mathrm{~h}$ with fresh pesticide for the treated groups as cypermethrin has been reported to be inactive after $72 \mathrm{~h}$ (Saha and Kaviraj 2008) and only water for the control group. Homogeneity was maintained in all the groups by providing similar experimental conditions. At the end of the experiment, livers were excised, weighed and the liver somatic index (LSI) was determined as percentage ratio of liver weight to body weight. The liver somatic index was calculated by using the formula: LSI = (liver weight/total live weight) $X 100$. As the liver samples were too small to be processed individually for enzyme activity, they were pooled (eight fish livers each) before homogenization.

\section{Microsome isolation}

Microsomes were isolated using the procedure described by Chang and Waxman (1998). Livers were perfused with a large volume of ice cold perfusion buffer $(1.15 \% \mathrm{KCl}, 1 \mathrm{mM}$ EDTA, $\mathrm{pH}$ 7.4) to get rid of unwanted tissues, fat bodies and blood and homogenized in four volumes of homogenization buffer $(1.15 \% \mathrm{KCl}, 1 \mathrm{mM}$ EDTA and $0.05 \mathrm{M}$ Tris, $\mathrm{pH}$ 7.4) using a teflon homogenizer. The homogenate was centrifuged in a cooling centrifuge at $12000 \mathrm{~g}$ for $20 \mathrm{~min}$. The supernatant was subjected to centrifugation at $100000 \mathrm{~g}$ for $60 \mathrm{~min}$ at $4^{\circ} \mathrm{C}$ in a super speed vacuum centrifuge. The resultant pellet were resuspended in two volumes of resuspension buffer containing $0.05 \mathrm{M}$ Tris, $1 \mathrm{mM}$ EDTA and $20 \%$ Glycerol v/v, pH 7.4 as the hepatic microsomal fraction.

\section{Enzyme assay}

Sectral analysis of CYP 450 was based on the mepthod described by Omura and Sato (1964). Protein in the microsomal fraction was estimated as described by Lowry et al. (1951) using bovine serum albumin as standard. Ethoxyresorufin Odeethylase (EROD) activity in the liver microsome samples was determined spectrophotometrically by the method of Klotz et al. (1984).

NNDMA activity was determined by the method of Schenkman et al. (1967) with minor modifications to detect CYP2B activity. Reaction mixture consisted of $100 \mathrm{mM} \mathrm{N}, \mathrm{N}$ dimethylaniline, $150 \mathrm{mM} \mathrm{MgCl} 2,100 \mathrm{mM}$ semicarbazide and microsomes $1.5-2.0 \mathrm{mg}$. The mixture was pre-incubated for $5 \mathrm{~min}$ at $32^{\circ} \mathrm{C}$ and the reaction started by adding $10 \mathrm{mM}$ NADPH. Following aerobic incubation for another $30 \mathrm{~min}$ the reaction was terminated by 
adding $0.5 \mathrm{~mL}$ each of $25 \%$ zinc sulfate and saturated barium hydroxide. Formaldehyde formed during the assay was measured by the method of Nash (1953) at $412 \mathrm{~nm}$.

Aniline hydroxylase activity (CYP2E1) was determined by measuring the amount of $\mathrm{p}$ aminophenol formed at $630 \mathrm{~nm}$. The method was modified from Imai et al. (1966) by using aniline $(10 \mathrm{mM})$ as substrate and NADPH $(10 \mathrm{mM})$ instead of an NADPH generating system. In addition, the incubation mixture consisted 100 $\mathrm{mM} \mathrm{MgCl} 2,120 \mathrm{mM}$ tris (pH 7.4) and 1.5-2.0 mg microsomal protein. After pre-incubation for 5 $\min$ at $32^{\circ} \mathrm{C}$, the reaction was initiated by the addition of NADPH and incubated for $30 \mathrm{~min}$.

Erythromycin demethylase (CYP3A4) activity was measured following the method of Werringloer (1978) at $412 \mathrm{~nm}$. The reaction was incubated at $32^{\circ} \mathrm{C}$ for $10 \mathrm{~min}$. Formaldehyde formed as the end product was measured by the method of Nash (1953) at $412 \mathrm{~nm}$. All the assays were done in duplicate.

\section{Statistical analysis}

Data were expressed as mean \pm standard deviation and were analyzed using one-way analysis of variance (ANOVA) followed by Dunnet's test. The statistical significance was tested at 5\% levels.

\section{RESULTS}

Total CYP 450 was significantly induced in all the three treated groups (5, 10 and 15 days) with higher induction seen in the groups with increasing number of days when compared to control (Table 1). The carbon monoxide difference spectra of dithionite reduced liver microsomes of $C$. punctatus were studied at $1 \mathrm{~min}$ interval over a period of 5 min (Fig. 1). The maximum absorbance was observed at 1 and 2 min and then gradual decrease in absorbance was seen with increase in time interval.

The LSI values were higher in all the treated groups (Table 1). EROD (CYP1A) activity was significantly induced in all the three treated groups with highest induction shown by the 15 days treated group as expected. The activity increased with the exposure time (Fig. 2).

Five and 10 days treated groups showed no significant increase in $\mathrm{N}, \mathrm{N}$-dimethylaniline $(\mathrm{N}$, N-DMA) demethylase (CYP2B) activity. The activity was significantly induced only in the 15 days treated group when compared to the control (Fig. 3).

No significant increase in aniline hydroxylase (CYP2E1) activity was observed in 15 days treated group whereas 5 and 10 days treated groups showed no induction (Fig. 4).

Table 1 - Total CYP 450 content and liver somatic index (LSI) of Channa punctatus.

\begin{tabular}{|c|c|c|c|c|c|c|}
\hline Parameter & control & 5 days & 10 days & 15 days & F-value & p-value \\
\hline $\begin{array}{l}\text { Total CYP450 content }(\mathrm{nmol} / \mathrm{mg} \\
\text { protein) }\end{array}$ & $0.276 \pm 0.089$ & $0.359 \pm 0.020^{*}$ & $0.382 \pm 0.042 *$ & $0.425 \pm .053^{*}$ & 6.190 & 0.003 \\
\hline Liver Somatic Index [LSI \%] & $0.914 \pm 0.113$ & $0.985 \pm 0.096$ & $1.009 \pm 0.120$ & $1.042 \pm .109$ & 1.924 & 0.155 \\
\hline
\end{tabular}

values are Mean $\pm \mathrm{SD}(\mathrm{n}=6)$. * significantly different from control

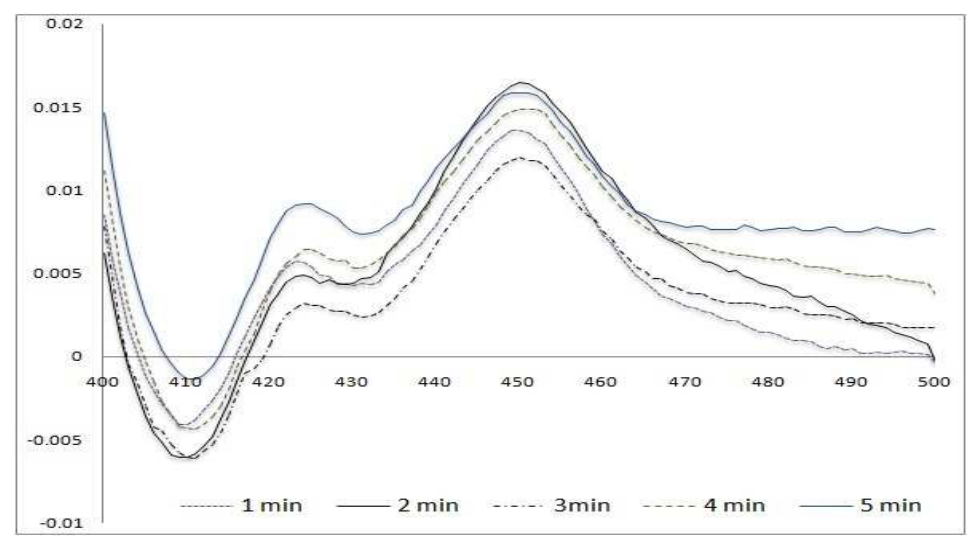

Figure 1 - Carbon monoxide difference spectra of dithionite reduced liver microsomes of Channa punctatus at $1 \mathrm{~min}$ interval over a period of $5 \mathrm{~min}$. 


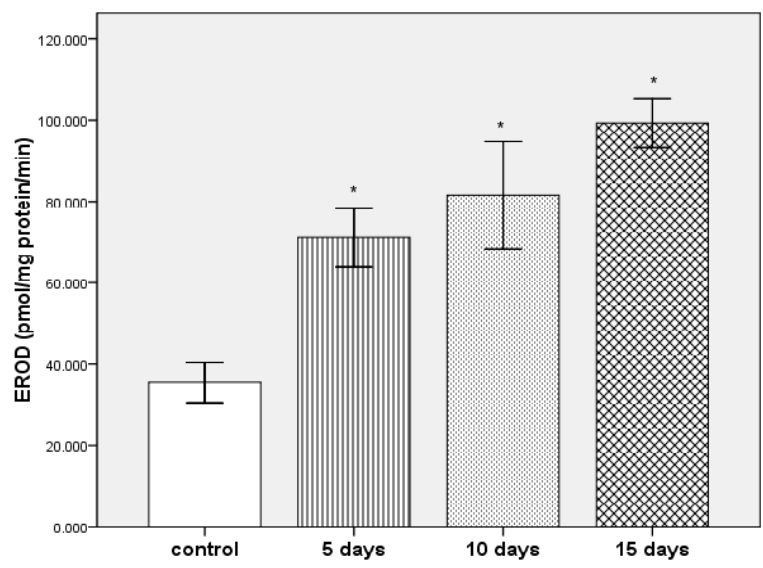

Figure 2 - CYP1A mediated EROD activity in liver of Channa punctatus. * indicates significant difference from control $(\mathrm{p}<0.05)$.

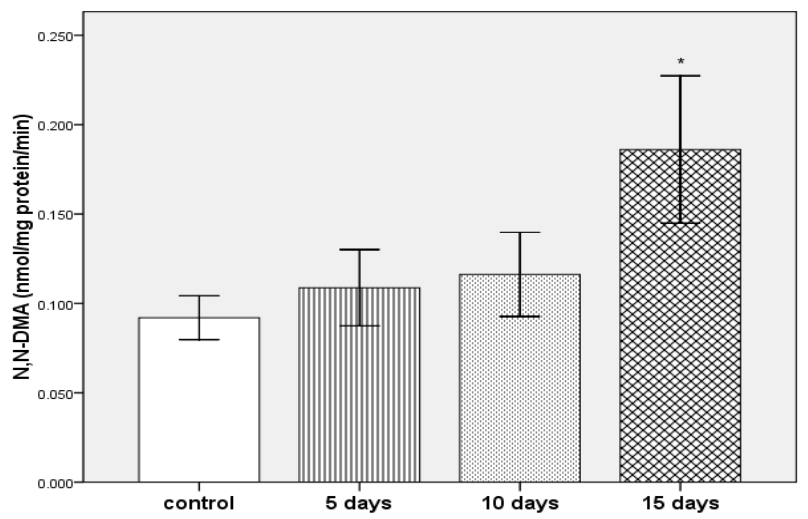

Figure 3 - CYP2B mediated N, N-dimethylaniline demethylase (N, N-DMA) activity in liver of Channa punctatus. *indicates significant difference from control $(\mathrm{p}<0.05)$.

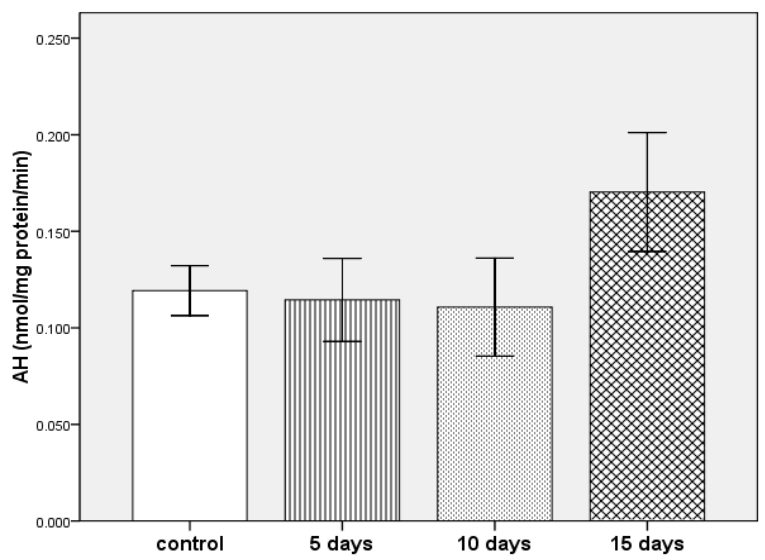

Figure 4 - CYP2E1 mediated aniline hydroxylase (AH) activity in liver of Channa punctatus.
All the three treated groups showed an inhibition in Erythromycin demethylase (CYP3A4) activity (Fig. 5). But only 10 and 15 days treated groups resulted in significant difference with respect to the control. The percentage of inhibition is shown in parenthesis.

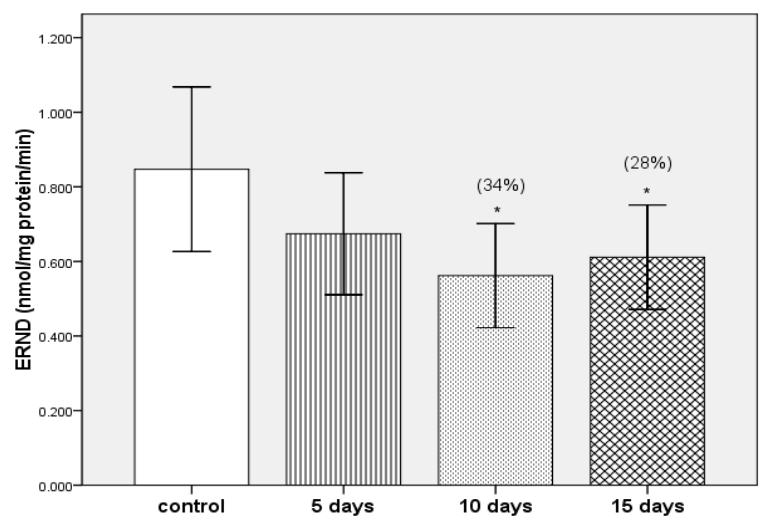

Figure 5-CYP3A4 mediated erythromycin demethylase (ERND) activity in liver of Channa punctatus. *indicates significant difference from control $(\mathrm{p}<0.05)$.

\section{DISCUSSION}

Hepatic CYP 450 expression of fish can be induced by exposure to xenobiotics because specific CYP1A expression is highest in this organ. Most lipophilic chemicals, including drugs, pesticides, carcinogens, environmental pollutants and naturally occurring compounds undergo enzyme-mediated oxidative, hydrolytic or conjugative biotransformation in liver and in extra hepatic tissues, yielding more polar metabolites that can be easily excreted. Thus, metabolism plays a critical role in determining both the efficacy and the residence time of drugs in the body as well as in modulating the response to toxic chemicals (Akdogan and Sen 2010).

Two soret peaks were seen in the dithionite reduced spectra of liver microsomes (Fig. 1). These peaks consisted of the characteristic absorbance at $450 \mathrm{~nm}$ for the reduced CYP 450$\mathrm{CO}$ complex and the other of lesser magnitude at around $420-425 \mathrm{~nm}$, which could be possibly due to the absorbance of contaminating hemoglobin since tissues could not be adequately perfused (Klemz et al. 2010).

Liver somatic index (LSI) has frequently been used as a biomarker for examining fish exposed to contaminants. LSI values are generally elevated in 
the vertebrates experiencing induction of hepatic microsomal P450 for the detoxification of organic compounds and LSI is generally used to determine the physiological status of the fish (Shailaja et al. 2006). Increase in LSI is commonly seen in fish exposed for long periods of time to organic contaminants in the laboratory and field. The increase in LSI can be due to hyperplasia (increased cell number) and/or hypertrophy (increased cell size). It may be associated with increased capacity to metabolize xenobiotics so it could be considered as adaption to the presence of pollution rather than a dysfunction (Heath 1995).

Enzyme activity increases with increase in exposure period to the xenobiotics as it brings about the physiological differences within the organism (Arellano-Aguilar et al. 2009). Each isoform of the cytochrome $\mathrm{P} 450$ participates in the metabolism of many different compounds, but one substrate can also be metabolized by several different isoforms (Siroka and Drastichova 2004). CYP1A subfamily is the most studied CYP 450 isoform and is responsible for a wide range of xenobiotic biotransformation whose catalytic activity is expressed as activity of EROD. In this study, the EROD activity was induced in all the treated groups, probably due to EROD`s higher detection sensitivity. Well-established inducers of CYP1A and EROD are organic contaminants belonging to PCBs, PAHs, PCDDs and PCDFs. However, induction by pesticide compounds has also been reported (Haluzova et al. 2011).

Bhutia et al. (2010) reported the absence of CYP2B in fish, $H$. fossilis as it did not respond to the mammalian specific CYP2B inducer, Phenobarbital. However, Stegeman et al. (1997) reported the presence of CYP2B like activities in four tropical fish species using catalytic activity assay and detection of the CYP2B protein by an immunoblot assay. Similarly, Bhutia et al. (2013) also reported the induction of CYP2B like activities in fish, $H$. fossilis after exposure to pesticide, cypermethrin. It is likely that some P450s differ in their functions among the mammals and fish and follow different mechanisms of induction. In consequence, whenever P450 enzymes are used as biomarkers in monitoring programs, one should be cautious with metabolic differences, even among fish species.

CYP2E1 mediated p-hydroxylation has been shown to be a possible pathway for the metabolism of xenobiotics in the liver of fish species. This activity can be detected by studying in vitro transformation of toxic aniline to nontoxic derivative $p$-aminophenol (Zen and Korkmaz 2009). Although, CYP2E1 is responsible for the metabolism and potential bioactivation of a number of low-molecular-weight pharmaceutical and other xenobiotic compounds, including acetaminophen, ethanol, isoniazid, halogenated anesthetics, acetone, and benzene (Omiecinski et al. 1999), a study by Bhutia et al. (2013) has reported its role in metabolism of pesticide with long-term exposure. This study showed the inhibition of CYP3A4 activity which was somewhat surprising given that CYP3A is one of the most abundant P450 isoform in fish liver possessing a broad range of substrate specificity (Hegelund and Celander 2003) and accounts for the metabolism of almost $50 \%$ of the currently used pharmaceutical agents (Parkinson 1996). This could also be the reason for high toxicity of pyrethroid insecticide in fish species as CYP3A4 was reported to be induced in Labeo rohita (Rai et al. 2010) and channel catfish (Stuchal et al. 2006) after exposure to chlorpyriphos and methoxychlor.

The present study clearly demonstrated the usefulness of CYP 450 as an important biomarker for monitoring the aquatic pollution. Of all the CYP 450 isoforms (CYP1A, CYP2B, CYP2E1 and CYP3A4), CYP1A was the most sensitive isoform towards cypermethrin toxicity and in accordance to various other studies as one of the most established biomarker of CYP 450 family.

\section{ACKNOWLEDGMENTS}

The author (Dawa Bhutia) is highly grateful and would like to thank University Grants commission, New Delhi, India for providing UGC-Meritorious Fellowship during the course of this work. The authors would also like to thank the Head of Department of Zoology, N.B.U. for the laboratory facilities provided during the course of the work.

\section{REFERENCES}

Akdogan HA, Sen A. Characterization of drug metabolizing enzymes and assessment of aging in the gilthead seabream (Sparus aurata) liver. Vet Med. 2010; 55(9): 463-471.

Arellano-Aguilar O, Montoya RM, Garcia CM. Endogenous Functions and Expression of Cytochrome P450 Enzymes in Teleost Fish: A Review. Rev Fish Sci. 2009; 17(4): 541-556. 
Bhutia D, Rai BK, Pal J. Multiple forms of Cytochrome P450 family in liver of fresh water teleost fish Heteropneustes fossilis (Bloch). NBU J Anim Sci. 2010; 4: 28-35.

Bhutia D, Rai BK, Pal J. Detection of Multiple Cytochrome $\mathrm{P} 450$ in Hepatic tissue of Heteropneustes fossilis (Bloch) Exposed to Cypermethrin. Proc Zool Soc. 2013; 66(1):14-19.

Chang TKH, Waxman DJ. Enzymatic analysis of cDNA-expressed human CYP1A1, CYP1A2, and CYP1B1 with 7-ethoxyresorufin as a substrate. In: Phillips IR, Shephard EA. Editors. Methods in Molecular Biology: Cytochrome P450 Protocols, Vol. 107, Totowa: Humana Press Inc.; 1998. p. 103-109.

Haluzova I, Modra H, Blahova J, Havelkova M, Siroka Z, Svobodova Z. Biochemical markers of contamination in fish toxicity tests. Interdiscip Toxicol. 2011; 4(2): 85-89.

Heath A G. Water Pollution and Fish Physiology. Second edition. Florida: CRC Press Inc.; 1995.

Hegelund T, Celander MC. Hepatic versus extrahepatic expression of CYP3A30 and CYP3A56 in adult killifish (Fundulus heteroclitus). Aquat Toxicol. 2003; 64(3): 277-291.

Imai Y, Ito A, Sato R. Evidence for biochemically different types of vesicles in the hepatic microsomal fraction. J Biochem. 1966; 60(4): 417-428.

Ioannides C, Lewis DFV. Cytochromes P450 in the Bioactivation of Chemicals. Curr Top Med Chem. 2004; 4: 1767-1788.

Klemz C, Salvo LM, Neto J da CB, Bainy ACD, Assis $\mathrm{HC}$ da S da. Cytochrome P450 Detection in Liver of the Catfish Ancistrus multispinis (Osteichthyes, Loricariidae) Braz Arch Biol Technol. 2010; 53(2):361-368.

Klotz AV, Stegeman JJ, Walsh C. An alternative 7ethoxyresorufin O-deethylase activity assay: a continuous visible spectrophotometric method for measurement of cytochrome P450 monooxygenase activity. Anal Biochem. 1984; 140(1): 138-145.

Lowry OH, Rosenbrough NS, Farr AL, Randall RJ. Protein measurement with the Folin phenol reagent. $J$ Biol Chem. 1951; 193(1): 265-275.

Moore NM, Depledge MH, Readman JW, Leonard DRP. An integrated biomarker-based strategy for ecotoxicological evaluation of risk in environmental management. Mutat Res. 2004; 552: 247-268.

Nash T. The colorimetric Estimation of Formaldehyde by means of the Hantzsch Reaction. Biochem J. 1953; 55(3): 416-421.

Omiecinski CJ, Remmel RP, Hosagrahara VP. Concise Review of the Cytochrome P450s and their Roles in Toxicology. Toxicol Sci. 1999; 48(2): 151-156.

Omura J, Sato R. The carbon monoxide binding pigment of liver microsomes. I. Evidence for its heme protein nature. J Biol Chem. 1964; 239(7): 23702378.
Parkinson A. Biotransformation of xenobiotics. In: Klaassen CD, Editor. Casarett and Doull's Toxicology: The Basic Science of Poisons, 5th ed. New York: McGraw-Hill; 1996. p. 113-186.

Rai BK, Bhutia D, Pal J. Cytochrome P450 in liver of Indian major carp, (Labeo rohita, Ham.) following sub-lethal exposure of chlorpyriphos. NBU J Anim Sc.2010; 4: 22-27.

Saha S, Kaviraj A. Acute toxicity of synthetic pyrethroid cypermethrin to some freshwater organisms. Bull Environ Contam Toxicol.2008; 80(1): 49-52.

Saha S, Kaviraj A. Effects of cypermethrin on some biochemical parameters and its amelioration through dietary supplementation of ascorbic acid in freshwater catfish Heteropneustes fossilis. Chem. 2009; 74(9): 1254-1259.

Schenkman JB, Remer H, Stabrook RW. Biochemical assay of cytochrome P-450. Mol Pharmacol. 1967; 3: 113-126.

Shailaja MS, Rajamanickam R, Wahidulla S. Increased formation of carcinogenic PAH metabolites in fish promoted by nitrite. Environ Pollut. 2006; 143(1): 174-177.

Sharma DK, Ansari BA. Effect of Deltamethrin and a Neem Based Pesticide Achook on Some Biochemical Parameters in Tissues Liver, Ovary and Muscle of Zebrafish, Danio rerio (Cyprinidae), Res. J Chem Sci. 2011;1(4): 125-134.

Siroka Z, Drastichova J. Biochemical Markers of Aquatic Environment Contamination -Cytochrome P450 in Fish. A Review. Acta Veterinaria Brno. 2004; 73: 123-132.

Stegeman JJ, Woodin BR, Singh H, Oleksiak MF,Celander M. Cytochromes P450 (CYP) in tropical fishes: catalytic activities, expression of multiple CYP proteins and high levels of microsomal P450 in liver of fishes from Bermuda. Comp Biochem Physiol C Pharmacol Toxicol Endocrinol. 1997; 116(1): 61-75.

Stuchal LD, Kleinow KM, Stegeman JJ, James MO. Demethylation of the pesticide methoxychlor in liver and intestine from untreated, methoxychlor-treated, and 3-methylcholanthrene treated channel catfish (Ictalurus punctatus): Evidence for roles of CYP1 and CYP3A family isozymes. Drug Metab Dispos. 2006; 34(6): 932-938.

Werringloer J. Assay of fomaldehyde generated during microsomal oxidation reactions. Methods Enzymol. 1978; 52: 297-302.

Zen T, Korkmaz H. The effects of Urtica Dioica L. leaf extract on aniline 4-hydroxylase in mice. Acta Pol Pharm. 2009; 66(3): 305-309. 